Article

\title{
ScFvs as Allosteric Inhibitors of VEGFR-2: Novel Tools to Harness VEGF Signaling
}

\author{
Kurt Ballmer-Hofer * (D), Caroline A.C. Hyde, Thomas Schleier and Dragana Avramovic* \\ Laboratory of Biomolecular Research, Paul Scherrer Institut, 5232 Villigen, Switzerland; \\ cachyde@gmail.com (C.A.C.H.); thomschleier@gmail.com (T.S.) \\ * Correspondence: kurt.ballmer-hofer@unibas.ch (K.B.-H.); dragana_avramovic@yahoo.com (D.A.); \\ Tel.: +41-61-6833-905 (K.B.-H.); +41-78-6868-547 (D.A.)
}

Received: 30 March 2018; Accepted: 23 April 2018; Published: 1 May 2018

\begin{abstract}
Vascular Endothelial Growth Factor Receptor 2 (VEGFR-2) is the main mediator of angiogenic signaling in endothelial cells and a primary responder to VEGF. VEGF dependent VEGFR-2 activation regulates endothelial cell migration and proliferation, as well as vessel permeability. VEGF is presented as an antiparallel homodimer, and its binding to VEGFR-2 brings two receptors in close proximity. Downstream signaling is triggered by receptor dimerization, kinase activation, and receptor internalization. Our aim was to further investigate allosteric inhibition using binders targeting extracellular subdomains 4-7 of VEGFR-2 as an alternative to existing anti-angiogenic therapies, which rely on neutralizing VEGF or blocking of the ligand-binding site on the receptor. We applied phage display technology to produce single chain antibody fragments (scFvs) targeting VEGFR-2. Selected antibody fragments were characterized using biophysical and biological assays. We characterized several antibody fragments, which exert their inhibitory effect of VEGFR-2 independent of ligand binding. These reagents led to rapid clearance of VEGFR-2 from the cell surface without kinase activation, followed by an increase in intracellular receptor-positive vesicles, suggesting receptor internalization. Our highly specific VEGFR-2 binders thus represent novel tools for anti-angiogenic therapy and diagnostic applications.
\end{abstract}

Keywords: angiogenesis; VEGFR-2; VEGF; scFv; inhibition; receptor downregulation

\section{Introduction}

Angiogenesis is the process of creation of new blood capillaries from pre-existing vasculature. It occurs throughout the life of higher organisms, in both healthy and pathological conditions.

Metabolically active tissues require blood vessels in close proximity for exchange of nutrient and metabolites. Owing to the fact that aberrant angiogenesis is implicated in a number of pathologies, research interest in its therapeutic control has steadily increased over the past decades. Approaches which deal with insufficient angiogenesis carry curative potential for ischemic heart disease, peripheral arterial disease, and wound healing, whereas excessive angiogenesis can be targeted in pathologies such as cancer, certain ophthalmic conditions, and rheumatoid arthritis.

Vascular endothelial growth factors (VEGFs) and their receptors (VEGFRs) are required for vascular and lymphatic homeostasis, but their aberrant signaling can give rise to pathological angiogenesis. Different members of the VEGF protein family bind VEGFR-1, -2, and -3, respectively, thereby regulating endothelial cell survival, proliferation, differentiation, and migration. VEGFR-2 is the major mediator of angiogenic signaling in endothelial cells, hence various tactics to target VEGF/VEGFR-2 signaling have been developed. However, most currently used strategies show significant side effects. Inhibition of VEGF signaling by ligand sequestering agents (bevacizumab) [1] or VEGFR-2 blocking antibodies (ramucirumab) [2,3] can be bypassed by high ligand concentration. 
On the other hand, classical low molecular weight tyrosine kinase inhibitors, such as sunitinib, widely used to suppress VEGFR-2 activity, are not exclusively specific for VEGFR-2 [4].

The extracellular domain (ECD) of VEGF receptors comprises seven immunoglobulin homology domains (Ig-domains). Previous studies have shown that domains D2 and D3 of the ECD are required for ligand binding $[5,6]$ while D4-7 are required for receptor dimer stabilization and the orientation of receptor monomers in active dimers $[7,8]$. The significance of such homotypic interactions in the receptor ECD, for VEGFR-2 activation, has been previously demonstrated and reported by our group [7-10]. Consequently, targeting of allosteric regulatory sites in D4-7 of VEGFR-2 by mutation or using inhibitory molecules, such as DARPins [11,12] and antibodies [13], have demonstrated successful inhibition of VEGF signaling.

Phage-displayed scFvs offer several advantages compared to full-size monoclonal antibodies, including inexpensive production in E. coli, simple genetic modification [14], and reduced immunogenicity. The smaller size of $\mathrm{scFv}$ fragments compared to full-size immunoglobulins provides fast target delivery and even penetration into target tissues, e.g., into tumors $[15,16]$. Since scFvs are more readily cleared from circulation, their exposure to healthy tissue is vastly reduced [17,18], making their application particularly attractive for imaging [19], drug delivery [20,21], and radionuclide- or drug-coupled nanobody delivery. Furthermore, scFv selection and production can be standardized, and thereby lends itself to automated and high throughput approaches [14].

The work presented in this study is based on our past functional characterization of VEGFR-2 activation. Our new reagents specifically target D4-7 of the ECD. We describe the production and characterization of $\mathrm{scFv}$ antibody fragments, and their effect on receptor kinase activity and receptor trafficking. In addition, we studied the biological output of VEGFR-2 following scFv administration in vitro.

\section{Results}

\subsection{Selection, Production, and Purification of ScFv Antibodies}

The synthetic ETH-2 Gold library was used for three rounds of selection of scFvs against hVEGFR-2. A total of 288 single clones were tested with ELISA, and 40 clones recognizing domains of interest were sequenced. ScFvs bearing unique sequences were further characterized. Three scFvs targeting different extracellular subdomains were chosen for further analysis (Table 1). ScFvs G3 and F1 were generated with the ETH-2 Gold phage library [22] using human VEGFR-2 ECD as antigen. ScFv A7 [23], previously selected and characterized by Böldicke et al., was selected with an antigen-biased immune V-gene phage display library which originated from murine lymphocytes, and was subcloned into pDN332 vector. As scFvs G3 and F1 were selected from an entirely different library than scFv A7, the sequences also differ. E. coli strain Mach-1 was used for large scale production, where soluble scFvs were purified utilizing an Äkta system with metal (Ni; scFv A7) or protein affinity chromatography (protein A; scFv G3 and scFv F1).

Table 1. Summary table showing CDR3 sequences of heavy and light chains, ETH-2 Gold library, domain specificities, and binding affinities of selected scFvs.

\begin{tabular}{cccccc}
\hline ScFv Clones & CDR3 $_{\mathbf{H}}$ & CDR3 $_{\mathbf{L}}$ & ScFv Library & $\begin{array}{c}\text { VEGFR-2 Domain } \\
\text { Specificity }\end{array}$ & $\begin{array}{c}\text { Binding Affinity } \\
\text { Kd (nM) }\end{array}$ \\
\hline G3 & P G F S A & D P R G A H & DP47DPL16 & Domain 6 & 137 \\
F1 & P G A S A & A P G G A Y & DP47DPL16 & Domain 7 & 6800 \\
A7 & GLWGGMDY & QQWNTYPYT & Mouse synthetic V-gene & Domains 2-3 & 92.6 \\
\hline
\end{tabular}

\subsection{Binding of ScFus to Recombinant and Endogenous VEGFR-2}

Binder specificity was investigated with ELISA using different length constructs of human VEGFR-2 (hVEGFR-2) ECD, whereas mouse VEGFR-2 (mVEGFR-2) ECD served as negative control (Figure 1a). Selected antibody fragments G3 and F1 were specific for human D6 and D7, respectively, 
but were not binding mVEGFR-2 ECD. The binding specificity for scFv A7 was defined by size-exclusion chromatography (SEC) (Figure S1) where scFv A7 was incubated with different length constructs of VEGFR-2 ECD and purified on a Superdex S-200. Collected peak fractions were concentrated and resolved on $12 \%$ SDS-PAGE gels. ScFv A7 recognized all constructs containing D2-3. Fluorescence size-exclusion chromatography (FSEC) (Figure 1b) shows a shift of the peak to the left, demonstrating the formation of larger protein complexes. This indicates that scFvs bound, but did not disrupt, the VEGFR-2 ECD/VEGF complex, illustrating that scFvs and VEGF did not compete for the binding site. Binding to live cells was observed in transiently VEGFR-2 transfected HEK293 cells by immunostaining. Here, we used commercially available antibodies to label VEGFR-2 and to visualize scFvs binding to the receptor on the cell surface. The green signal represented VEGFR-2 immunostaining with primary VEGFR-2-specific antibody and secondary fluorescently-labeled antibody. The red signal represented binding of myc- and flag-tag antibodies to scFvs G3 and F1, and scFv A7, respectively, accompanied with the fluorescently-labeled secondary antibody. Non-transfected HEK293 cells were used as negative control. Altogether, this data confirmed that scFvs recognize VEGFR-2 on the surface of the cells (Figure 2). Affinities of the scFvs were measured by isothermal titration calorimetry (ITC) (Figure S2). The advantage of using ITC compared to surface plasmon resonance (SPR) is that both binding players are in solution, and that the binding affinities are measured directly during binding. The calculated $\mathrm{Kd}$ values are summarized in Table 1.

\subsection{Functional Inhibition of VEGFR-2 Phosphorylation with ScFvs}

We used kinase assays to functionally characterize selected antibody fragments. PAE-KDR cells that recombinantly express VEGFR-2 were exposed to increasing concentrations of scFvs in the presence of physiological concentrations of VEGF. Incubation with VEGF alone led to rapid VEGFR-2 phosphorylation (Figure 3), and that effect was inhibited by pretreatment with scFvs. Upon addition of scFv, VEGFR-2 phosphorylation was downregulated in a dose-dependent manner, without affecting overall VEGFR-2 expression. As signal output of VEGFR-2, we examined expression and phosphorylation of PLC $\gamma$, AKT, and p38 mitogen-activated protein kinase (MAPK). While PLC $\gamma$ phosphorylation was clearly inhibited, the level of AKT phosphorylation was only marginally affected by scFvs. VEGF-mediated activation of p38 did not show a statistically significant change upon scFv addition. Taken together, treatment of PAE-KDR cells with scFv antibody fragments suppressed VEGF-dependent receptor phosphorylation and downstream signaling in a dose-dependent manner without showing an effect on total protein levels (Figure 3a). 
(a)
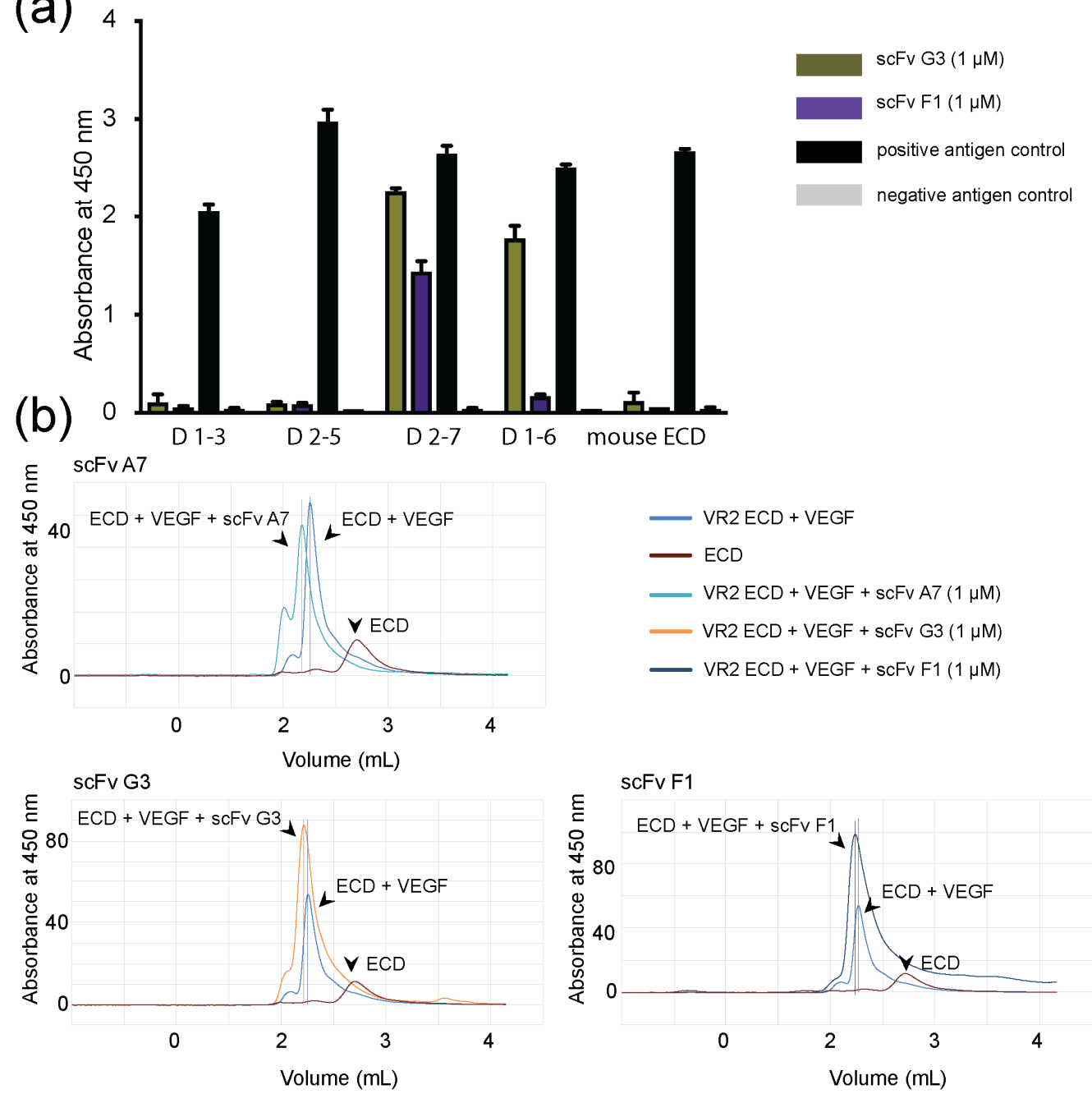

Figure 1. Analysis of scFv binding to the VEGFR-2 ECD (a) ELISA results show VEGFR-2 domain specificity, shown as absorbance at $450 \mathrm{~nm}$. ELISA plates were coated with different length VEGFR-2 ECD constructs and exposed to $1 \mu \mathrm{M}$ of scFvs. Absorbance signal represents specific binding of scFvs to VEGFR-2 ECD construct. Antigen controls demonstrate wells with and without VEGFR-2 ECD construct. Presented results are the mean of three independent experiments where error bars represent \pm standard deviation (SD); (b) Fluorescence size-exclusion chromatography results show ScFvs binding to VEGFR-2 ECD/VEGF complex. ScFvs $(1 \mu \mathrm{M})$ were incubated with VEGFR-2 ECD/VEGF complex, and the mixture was analyzed with FSEC. VEGFR-2 ECD/VEGF complex and VEGFR-2 ECD were used as controls. The incubation with scFvs led to the shift in the peak position to the left, demonstrating the formation of new larger species in combination with VEGFR-2 ECD/VEGF and the bound scFvs. ScFv addition did not lead to a shift in the peak position to the right, indicating that binding of scFvs did not disrupt the complex. 


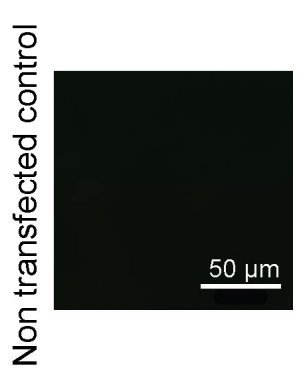

(a)

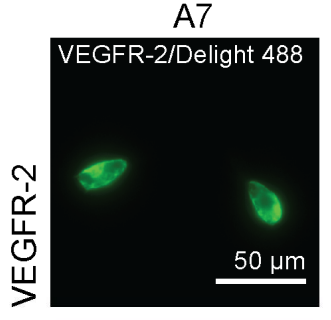

(b)

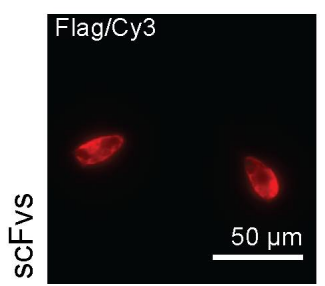

G3
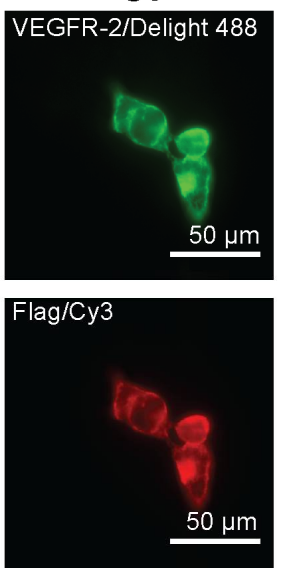

F1
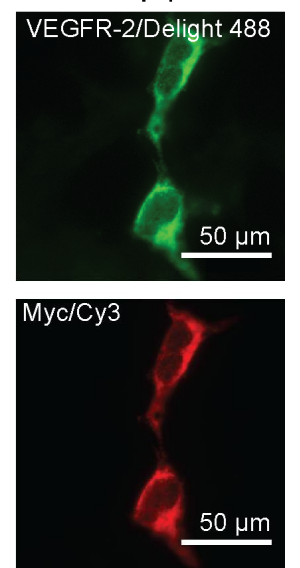

Figure 2. ScFvs bind VEGFR-2 expressed on the surface of HEK293 cells. (a) VEGFR-2 was detected with commercial primary VEGFR-2 antibody and fluorescently-labeled secondary antibody (green); (b) For ScFvs staining, myc-tag (scFvs G3 and F1) and flag-tag (scFv A7) primary antibodies were used, followed by secondary fluorescently-labeled antibodies (red). Bound ScFvs show the same binding pattern as commercial VEGFR-2 antibody. Non-transfected HEK293 cells were used as negative control.
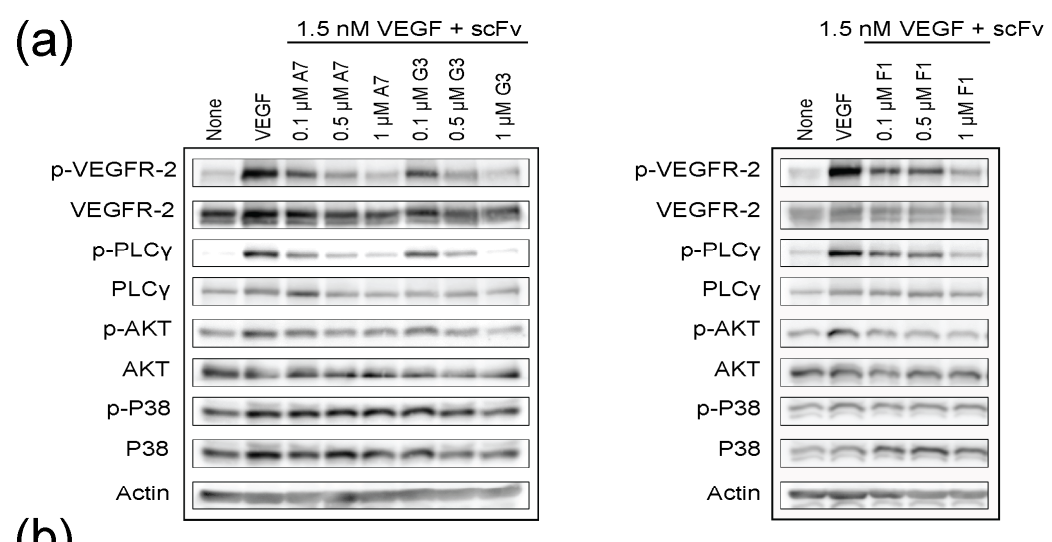

(b)

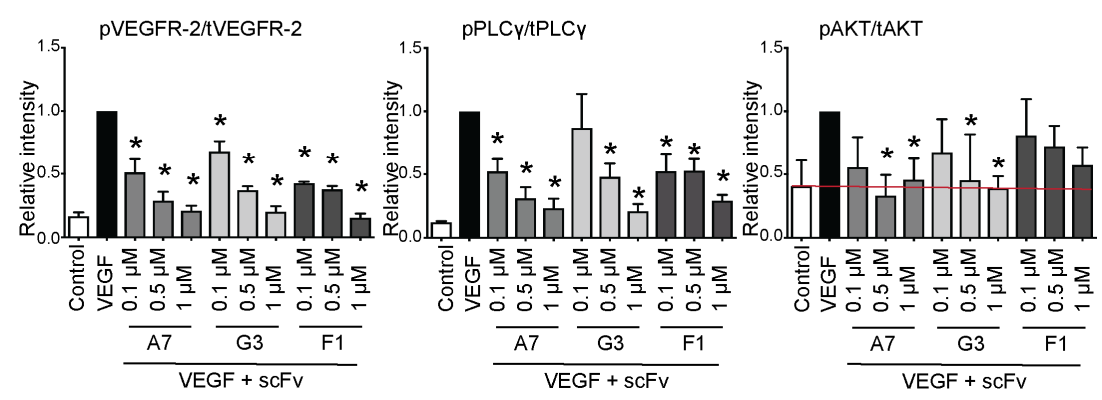

Figure 3. ScFvs inhibit VEGF-induced signaling in PAE-KDR cells. (a) Western blot results show the effect of pretreatment with increasing concentrations of scFvs and demonstrate inhibition of phosphorylation of VEGFR-2, PLC $\gamma$, and AKT in a dose-dependent manner, without affecting total protein levels; (b) Data was quantified with ImageJ and further analyzed with GraphPad Prism 7. Presented results are the mean of three independent experiments where error bars represent \pm standard deviation (SD). The statistical significance was investigated with ordinary 1-way ANOVA using Dunnett's test, and indicated by * representing $p<0.05$. The red line references non-stimulated control. 


\subsection{Effect of ScFvs on In Vitro Angiogenesis}

We examined the effect of our antibody fragments on the formation of capillary-like structures formed by endothelial cells exposed to VEGF. HUVECs were embedded in Matrigel incubated for $18 \mathrm{~h}$ in the presence or absence of scFvs. HUVECs incubated with VEGF-containing Matrigel led to the formation of tube-like structures, while treatment with increasing concentration of scFvs significantly inhibited this effect (Figure 4a). Endothelial cell migration in response to VEGF represents a critical step in the formation of new blood vessels. In wounded HUVEC monolayers, VEGF-induced migration was decreased upon treatment with scFvs (Figure S3).

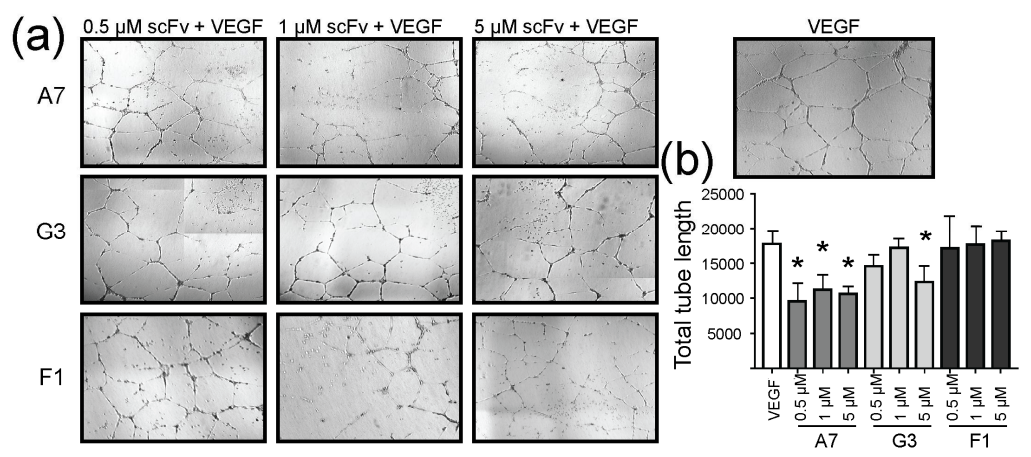

Figure 4. ScFvs inhibit VEGF-induced development of tube-like structures in HUVECs. (a) Microscopy images at $4 \times$ magnification show tubular structures formed in the presence of VEGF. Tube formation was disrupted in the presence of increasing concentrations of scFvs; (b) Image analysis quantifies the length of ligand-induced tubes in the presence and absence of $\mathrm{scFv}$ antibody fragments. Presented results are mean of three independent experiments, where error bars represent \pm standard deviation (SD). The statistical significance was investigated with ordinary 1-way ANOVA using Dunnett's test and indicated by * representing $p<0.05$.

\subsection{VEGF and ScFvs Promote Internalization of VEGFR-2}

Based on our recently published work on DARPin ${ }^{\circledR}$ VEGFR-2-domain D4b-induced receptor internalization [12], we studied scFv-induced internalization of VEGFR-2 in the presence and absence of VEGF. We used the same two approaches to determine receptor internalization as published [12]. First, we determined receptor uptake into intracellular vesicles in PAE-KDR cells and measured VEGFR-2 positive vesicle area (Figure 5). A significant increase of VEGFR-2 positive vesicle area upon addition of either VEGF or scFvs was observed.

To confirm that receptor internalization correlates with VEGFR-2 removal from the cell surface upon VEGF or scFv binding, we trypsinized membrane-bound receptor on intact cells. Membrane-bound extracellular VEGFR-2 was digested, while internalized protein was protected and remained intact. In untreated control cells, only full-length VEGFR-2 was observed (Figure 5c, lane 1), while trypsin treatment led to the degradation of the receptor in control cells, as indicated by the two lower bands (lane 2) of the SDS-PAGE gels. By contrast, VEGF or scFv A7 incubation led to VEGFR-2 protection from trypsin degradation, and predominantly the bands corresponding to intact VEGFR-2 were observed (lanes 3 and 4). ScFvs G3 and F1 induced partial VEGFR-2 internalization, and bands indicating protected and degraded receptor were present (lanes 5 and 6 ). These data agree with Squassh analysis of VEGFR-2 internalization (Figure 5a) showing a stronger internalization effect was induced with scFv A7, compared to scFvs G3 and F1. Furthermore, scFv A7 displayed a lower dissociation constant compared to scFvs G3 and F1, which mirrors its increased inhibitory effect observed at the functional level (Table 1). Moreover, we showed that scFv incubation, on its own, had no impact on VEGFR-2 activation (Figure 5d). 
In order to exclude that toxic side-effects were responsible for inactivation of VEGFR-2 signaling, cell viability assays were performed. All scFvs proved non-toxic at working concentrations of $0-10 \mu \mathrm{M}$, with a cell viability $>90 \%$ (data not shown).

So far, we showed the selection, production, and purification process, accompanied with biophysical and biological characterization of scFvs targeting VEGFR-2. The inhibitory effect of described antibody fragments was tested in kinase and angiogenesis assays. Moreover, we demonstrated that incubation with scFvs leads to ligand independent VEGFR-2 internalization.

(a)
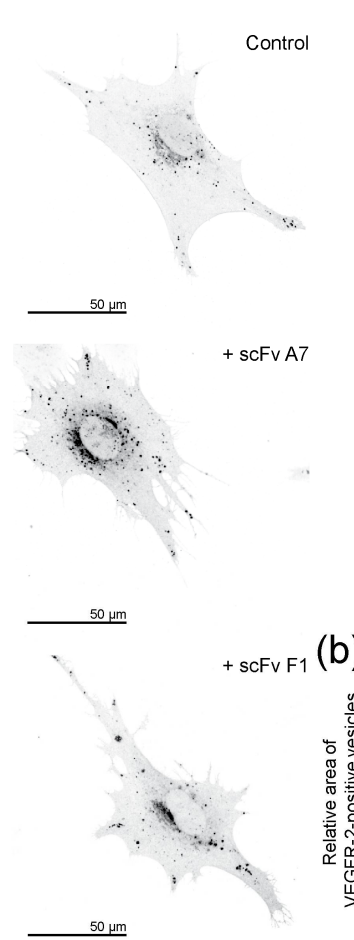

(c)

(d)

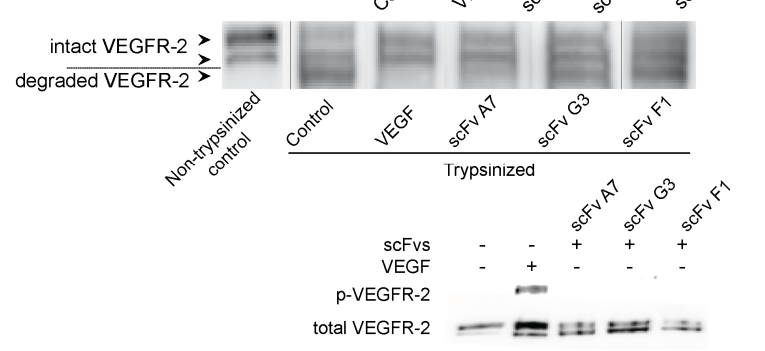

Figure 5. VEGF and scFvs promote VEGFR-2 internalization. (a) Immunostaining of VEGFR-2 expressing PAE-KDR cells show receptor internalization following VEGF or scFv administration. PAE-KDR cells were fixed and stained for 45 min after addition of VEGF or scFvs; (b) Area of VEGFR-2 positive vesicles relative to total cell area was analyzed by Squassh. Statistical data analysis was performed using GraphPad Prism 7. Data show representative images of 25 independent samples. Error bars represent $\pm \mathrm{SD}$. The statistical significance based on a Student's $t$-test is indicated by * representing $p<0.05$. The red line references non-stimulated control; (c) Western blot analysis of control and trypsin-treated cells using VEGFR-2-specific antibody. Cells were treated with VEGF or scFvs for $45 \mathrm{~min}$. Top two arrows on the left of the blot indicate bands representing intact receptor, bottom arrow points to band of degraded receptor. (d) Kinase assay. SDS-PAGE gel shows kinase activity of VEGFR-2 determined with phospho-tyrosine-specific antibody in PAE-KDR cells. As controls we showed non-stimulated and VEGF-stimulated kinase activation. Bottom row shows total level of VEGFR-2 for the same gel. 


\section{Discussion}

The VEGF/VEGFR-2 signaling axis represents an essential and attractive target to manipulate pathological angiogenesis in vivo. Ramucirumab is a monoclonal antibody developed from a human Fab antibody fragment targeting VEGFR-2 [24,25], and approved for the treatment of advanced gastric cancer, gastroesophageal junction adenocarcinoma cancer, non-small cell lung cancer, and metastatic colorectal cancer $[2,3,26,27]$. Furthermore, promising studies with antibodies and DARPins targeting VEGFR-2 have been previously published [11,13]. We set out to generate novel VEGF/VEGFR-2 inhibitors based on VEGFR-2 specific antibody fragments that allosterically block receptor activation.

Described antibody fragments specifically recognize different subdomains of the VEGFR-2 ECD. ScFvs A7, G3, and F1 exclusively target D2-3, D6, and D7, respectively. Selected scFvs showed species-specificity by recognizing both purified recombinant human receptor ECD protein and hVEGFR-2 transiently expressed on the surface of HEK293 cells. Antibody fragment binding did not disrupt VEGFR-2 ECD/VEGF complex formation, but rather gave rise to larger protein complexes, demonstrating that scFvs and VEGF bind to different sites on the receptor ECD. The best binders demonstrated affinities in the nanomolar range, comparable to those of previously published scFvs $[28,29]$. In order to use the described antibody fragments for further in vivo testing, additional optimizations, including affinity maturation, may be required. Alongside binding affinity, scFv stability may represent a further challenge. Various strategies were developed to address this issue, including the introduction of extra disulfide bonds [30,31], and modification of the peptide linker in both length and composition [32,33].

Nonetheless, we showed that the presently investigated ScFvs significantly suppressed VEGF-induced VEGFR-2 phosphorylation and downstream signaling. Selected antibody fragments also showed consistent inhibition of biological receptor output, such as inhibition of cell migration and tube formation of HUVECs, indicative of specific inhibition of VEGF-driven angiogenesis in vitro.

Most interestingly, internalization studies revealed a possible cellular mechanism of scFv-mediated VEGFR-2 inhibition. Recently, our group published results showing that DARPin ${ }^{\circledR}$ domain D4b induces VEGFR-2 internalization independently of VEGF [12]. Here, we show the same effect with scFvs targeting D2-3, D6, or D7 (Figure 5). Antibody fragments binding to VEGFR-2 led to receptor internalization, as demonstrated by an increase in the relative area of intracellular VEGFR-2-positive vesicles (Figure 5a), and the clearance of the receptor from the cell surface (Figure 5c) without an impact on VEGFR-2 activation (Figure 5d). Internalization independent of ligand binding and thus, of kinase-inactive receptor, represents a novel property of the scFvs described here. This finding indicates that internalization is not binder or domain specific, but is a shared property among all allosteric VEGFR-2 inhibitors studied in the course of our studies. The mechanism of receptor downregulation is shared with other receptor tyrosine kinase antibodies specific for HER2 or EGFR [34,35]. Drebin et al. [36] and Hudziak et al. [37] have shown that HER2-specific antibodies reduced the amount of receptor expressed on the surface of cancer cells. Similar to antibodies specific for HER2 [38], the allosteric effect of our scFvs might provoke structural changes in the receptor ECD resulting in receptor internalization and clearing from the plasma membrane. Previously, receptor clustering followed by unspecific internalization was also described for another HER2-specific antibody, pertuzumab [39]. We showed previously in live cells that VEGFR-2 forms dimers, also in the absence of ligand [40]. We assume, therefore, that receptor crosslinking is a possible mechanism underlying VEGFR-2 internalization.

Similarly to earlier described Ankyrin repeat-derived binding scaffolds [11,12], scFvs, due to their high specificity and selectivity, represent excellent tools for specifically targeting the extracellular domain of membrane-bound molecules. In addition, scFvs can be easily reformatted to Fab or full-size immunoglobulins to modulate bioavailability in a host organism. Due to the demonstrated receptor internalization property, such antibody fragments might also be useful as immunotoxin or nanoparticle-antibody conjugates to deliver therapeutic cargo to diseased cells. There are several 
scFv-based strategies undergoing preclinical and clinical trials at present [41-44], proving that such an approach reaches beyond basic research and is applicable for novel clinical applications.

\section{Materials and Methods}

\subsection{Cell Culture}

Porcine aortic endothelial cells overexpressing VEGFR-2 (PAE-KDR) and human embryonic kidney epithelial 293 cells (HEK293) were cultured as monolayers in Dulbecco's modified Eagle's medium (DMEM; BioConcept, Basel, Switzerland) enriched with 10\% fetal bovine serum (FBS) and 1\% penicillin streptomycin. Human umbilical vein endothelial cells (HUVECs; Lonza, Walkersville, MD, USA) were cultured in EGM-2 medium (Lonza). Cells were grown in humidified incubator at $37^{\circ} \mathrm{C}$ and exposed to $5 \% \mathrm{CO}_{2}$.

\subsection{Transient Transfection}

HEK293 cells at $60 \%$ confluency were transiently transfected with pBE plasmid bearing VEGFR-2 sequence with FuGENE (Promega, Madison, WI, USA) in Opti-MEM medium (Life Technologies, Carlsbad, CA, USA) in a 2:3 ratio of DNA/FuGENE. Immunostaining was performed $24 \mathrm{~h}$ after transfection. Antibodies used were as follows: tVEGFR-2 (ab11939, Abcam, Cambridge, UK), myc-tag (2276S, Cell Signaling, Danvers, MA, USA), flag-tag (F3165, Sigma-Aldrich, St. Louis, MA, USA). Fluorescently-labeled Dylight 488 and Cy3 were acquired from Abcam.

\subsection{VEGFR-2 Kinase Activity Assay}

Serum starved PAE-KDR cells were incubated for $10 \mathrm{~min}$ with $1.5 \mathrm{nM}$ VEGF (in all experiments VEGF-A 165 was used) with or without 30 min pretreatment with scFvs. Cells were lysed with lysis buffer (50 mM Tris (pH 7.5), $100 \mathrm{mM} \mathrm{NaCl}, 0.5 \%(w / v)$ Triton X-100) supplemented with protease inhibitor cocktail (Complete Mini EDTA-free, Roche) and phosphatase inhibitors (200 $\mu \mathrm{M} \mathrm{Na}_{3} \mathrm{VO}_{4}$, $20 \mu \mathrm{M}$ phenylarsine oxide). Lysates were diluted with $5 \times$ loading buffer $(0.25 \mathrm{M}$ Tris- $\mathrm{HCl} \mathrm{pH} 6.8$, $0.5 \mathrm{M}$ DTT, 10\% SDS, 50\% glycerol, $0.5 \%$ bromophenol blue). Samples were boiled at $50{ }^{\circ} \mathrm{C}$ for $30 \mathrm{~min}$, and resolved by 7\% SDS PAGE, transferred to PVDF membranes (GE Healthcare, Piscataway, NJ, USA), and immunodecorated with primary antibodies (dilution 1:1000), followed by secondary alkaline phosphatase-coupled antibodies (1:10000). Immunoblots were developed with Novex AP Chemiluminescent Substrate (Invitrogen, Carlsbad, CA, USA). Amersham Imager 600 (GE) was used for analysis. Antibodies used were as follows: pVEGFR-2 (2478, Cell Signaling), tVEGFR-2 (2479, Cell Signaling), pPLC $\gamma 1$ (2821, Cell Signaling), tPLC $\gamma 1$ (2822, Cell Signaling), pAKT (4060, Cell Signaling), tAKT (4051, Cell Signaling), p38 (4631, Cell Signaling), and tp38 (9212, Cell Signaling). Protein marker used was PageRuler ${ }^{\mathrm{TM}}$ Plus Prestained Protein Ladder, 10 to $250 \mathrm{kDa}$ (26619, ThermoFisher, Waltham, MA, USA).

\subsection{Immunofluorescence Microscopy}

Cells were grown to $60 \%$ confluency on glass coverslips coated with poly-L-lysine (P4707, Sigma-Aldrich). Cell fixation at $37{ }^{\circ} \mathrm{C}$ for $20 \mathrm{~min}$ was performed with $3.7 \%$ formaldehyde in phosphate-buffered saline (PBS), followed by 10 min permeabilization with $0.1 \%$ NP-40 in PBS, and 20 min blocking in 5\% BSA/PBS at room temperature. For immunostaining, primary and fluorescently-labeled secondary antibodies were diluted in blocking solution, and samples were embedded. Images were acquired with an Olympus IX81 equipped with an Andor iXonEM camera (Figure 2), and with Leica SP5 laser scanning confocal microscope (Figure 5).

\subsection{Phage Display and Selection of ScFv Antibodies}

The synthetic ETH-2 Gold library was kindly provided by Prof. Dario Neri from ETH, Switzerland. 
Phage display using the ETH-2 Gold phage library was performed as previously described [22,45]. In short, immunotubes (470319K, Nunc, Wiesbaden, Germany) were coated with extracellular domain of VEGFR-2 (made in-house) at a concentration of $10^{-6} \mathrm{M}$. Antigen-exposing tubes were incubated with the phage for $1 \mathrm{~h}$ at room temperature, followed by washing steps, performed to remove unbound and weakly bound phages. Specific binders were eluted, amplified in E. coli Tg1, and used for next two rounds of selection. After the third round, bacteria were diluted and plated to obtain single clones used for scFvs production from E. coli supernatants. ELISA was used to screen for binders to VEGFR-2 ECD, as described below. Positive binders with unique sequences were identified and used to infect the E. coli non-suppressor strain Mach1 for the large-scale production. ScFv A7, used in this study, was obtained from an antigen-biased immune V-gene phage display library generated from murine lymphocytes [23], and subcloned in pCANTAB 5E, as described below.

\subsection{Subcloning of $p$ CANTAB 5E ScFv A7}

The obtained scFv A7 was in the plasmid pCANTAB 5E [23]. To subclone it into the pDN332 vector, two-step PCR cloning was performed. Amplification primers were $\mathrm{pCpD-for} \mathrm{5'-GTT} \mathrm{ATT}$ ACT CGC GGC CCA GCC GGC CAT GGC CCA GGT GAA ACT GC AGG AGT C-3' and pCpD-rev 5'-TCC CCC CTG GTT CGA CCT CGA CTG GCA GGA TCC GCG CCG GCG TCT A-3'. NotI/SfiI (New England Biolabs) double digestion was carried, followed by ligation and transfection of $E$. coli Mach1 cells.

\subsection{Expression and Purification of ScFvs}

Soluble scFvs were expressed in E. coli Mach1 cultured at $37^{\circ} \mathrm{C}$ in $2 \times \mathrm{YT}$ medium supplemented with $0.1 \%$ glucose and $100 \mu \mathrm{g} / \mathrm{mL}$ ampicillin. When bacterial growth reached $0.8 \mathrm{OD} 600$, the expression was induced with $1 \mathrm{mM}$ IPTG. E. coli was further propagated at $30{ }^{\circ} \mathrm{C}$ for $10 \mathrm{~h}$, followed by centrifugation at $4000 \mathrm{~g}$. A fully-automated liquid chromatography instrument Äkta (GE Healthcare) was used for affinity chromatography purification. ScFv-enriched supernatant was filtered and purified with immobilized metal affinity chromatography (IMAC) using protein A (GE) or with Ni-affinity chromatography (GE). Buffers used were as follows. For protein A chromatography purification: binding buffer, $20 \mathrm{mM}$ Tris $\mathrm{pH}$ 8.0; washing buffer, $20 \mathrm{mM}$ glycine $\mathrm{pH}$ 6.0; and elution buffer, $0.1 \mathrm{M}$ glycine $\mathrm{pH}$ 2.5. For Ni-affinity chromatography purification: binding buffer, $50 \mathrm{mM}$ sodium phosphate, $300 \mathrm{mM} \mathrm{NaCl}, 10 \mathrm{mM}$ imidazole, $\mathrm{pH}$ 7.4; and elution buffer, $50 \mathrm{mM}$ sodium phosphate, $300 \mathrm{mM}$ $\mathrm{NaCl}, 500 \mathrm{mM}$ imidazole, $\mathrm{pH}$ 7.4. Eluted fractions $(2 \mathrm{~mL})$ containing scFvs were pooled together, concentrated up to $1 \mathrm{mg} / \mathrm{mL}$, and dialyzed overnight against PBS, $\mathrm{pH} 7.4$, at $4{ }^{\circ} \mathrm{C}$. NanoDrop A280 measurements were used for estimating soluble protein concentrations, and the obtained yield of scFvs was in the range of $1-4 \mathrm{mg}$ from $1 \mathrm{~L}$ of bacterial culture.

\subsection{Enzyme-Linked Immunosorbent Assay (ELISA)}

Recombinant VEGFR-2 ECD proteins D1-3, D2-5, D2-7, and D1-6 were used in ELISA to determine binders' specificity for specific VEGFR-2 ECD subdomains. Maxisorp plates (Nunc) were coated overnight with $3 \mathrm{~g} / \mathrm{mL}$ of the antigen. Extensive washing steps performed to avoid false positive signal were followed by blocking in PBS/1\% BSA/0.1\% Tween 2 and exposure to $1 \mu \mathrm{M} \mathrm{scFvs}$ for $2 \mathrm{~h}$ at room temperature. As scFvs G3 and F1 were caring myc-tag, myc-tag antibody (2276S, Cell Signaling) as primary and anti-mouse IgG HRP-linked (7074S, Cell Signaling) as secondary antibodies were used for binding detection. All used antigens were His-tagged, hence, we used His-tag $(34,660$, Qiagen, Hilden, Germany) as primary antibody and anti-mouse IgG HRP-linked as secondary antibody to detect antigen immobilization on the plate surface. As negative control, we used wells without antigen. Reaction was induced by peroxidase substrate (ThermoFisher) and quenched by $2 \mathrm{M}$ sulfuric acid $\left(\mathrm{H}_{2} \mathrm{SO}_{4}\right)$. An automated plate reader (TECAN Safire2) was used to measure OD450 value. 


\subsection{Size-Exclusion Chromatography (SEC)}

SEC was performed with a Superdex S-200 size exclusion column (Amersham Pharmacia Biotech, Dübendorf, Switzerland). Samples (500 $\mu$ L) containing scFv A7 and VEGFR-2 ECD variants at a molar ratio of 2:1 were incubated at $4{ }^{\circ} \mathrm{C}$ and injected onto the column. HEPES buffer was used for protein separation, and protein absorption was detected at $280 \mathrm{~nm}$.

\subsection{Fluorescence Size-Exclusion Chromatography (FSEC)}

Ultracentrifuged samples in PBS were applied to a Shodex semi-micro KW404-4F (4.6 ̊ 300 mm) column, pre-equilibrated with PBS, pH 7.4 at $4{ }^{\circ} \mathrm{C}$. The fractions from the SEC column were passed through a fluorometer (FLD1: excitation/emission 435/470 nm, gain 12; FLD2: excitation/emission $515 / 535 \mathrm{~nm}$, detector gain 10). Data was analyzed with OriginLab (Origin 9.1).

\subsection{Binding Affinity Determination by Isothermal Titration Calorimetry (ITC)}

The binding enthalpy of scFv proteins was assessed by ITC carried out on a iTC200 calorimeter (MicroCal ${ }^{\circledR}$, Northampton, UK). Experiments were performed at $15^{\circ} \mathrm{C}$. Prior to use, all protein samples were dialyzed extensively against working solution (PBS) and degassed for $10 \mathrm{~min}$. VEGFR-2 ECD protein $(15 \mu \mathrm{M})$ was used as a titrant in the cell, and the scFvs $(400 \mu \mathrm{M})$ were used as titrants in the syringe at a tenfold higher concentration. Data was processed with the OriginTM 8.0 software (Microcal Inc., Northampton, MA, USA), using non-linear fitting models to calculate the reaction stoichiometry $(\mathrm{N})$, binding constant $(\mathrm{K})$, enthalpy $(\mathrm{DrH})$, and entropy $(\mathrm{DrS})$.

\subsection{HUVEC Tube Formation Assay}

For tube formation assays, commercially available 15-well $\mu$-Slides (Ibidi, Munich, Germany) were precoated with Geltre ${ }^{\circledR}$ Matrix (ThermoFisher). After the matrix polymerized, 6000 HUVECs were plated on the plates and maintained in previously described conditions. Increasing concentrations $(0.5,1$, and $5 \mu \mathrm{M})$ of scFvs were used to test the inhibiting potential. After $18 \mathrm{~h}$, the plates were fixed with $3.7 \%$ formaldehyde (FA). Previously described Olympus IX81 microscope was used for obtaining images of tubes-like structures. Images were analyzed using automated image analysis software (http://ibidi.wimasis.com/).

\subsection{HUVEC Migration Assay}

For migration assays, Culture-Inserts from Ibidi, Germany, were used. 21,000 HUVECs were seeded in each chamber and maintained in previously described conditions. The following day, culture inserts were removed, and cells were stimulated with VEGF in the presence and absence of increasing concentrations of scFvs $(0.5,1$, and $5 \mu \mathrm{M})$. The previously described Olympus IX81 microscope was used for obtaining images of migrating cells.

\subsection{Squassh Analysis of VEGFR-2 Internalization}

We used Squassh [46] to segment intracellular vesicles of 25 cells per condition, as previously described [12]. Squassh represents an ImageJ plugin that combines segmentation and deconvolution of images in a single step, yielding better results for small objects close to the diffraction limit of the microscope. Squassh Analyst was used for data analysis and normalization of the VEGFR-2 positive vesicle area relative to the total cell area. Prior to Squassh analysis, cells were treated either with $1.5 \mathrm{nM}$ VEGF or $1 \mu \mathrm{M}$ scFvs for $45 \mathrm{~min}$ in starvation media. Used antibodies were VEGFR-2-specific antibody (2479, Cell Signaling) as primary, and fluorescently-labeled Dylight 488 (Abcam) as secondary antibody.

\subsection{Trypsin Digestion of Cell Surface-Exposed Receptors}

PAE-KDR cells were cultured in standard previously described conditions prior starvation and 45 min treatment with $1.5 \mathrm{nM}$ VEGF or $1 \mu \mathrm{M}$ scFvs. Cells were consequently washed three times with 
ice-cold PBS, and then incubated for $30 \mathrm{~min}$ at $4{ }^{\circ} \mathrm{C}$ with freshly prepared trypsin $(1 \mathrm{mg} / \mathrm{mL}$, Sigma). The enzymatic reaction was quenched by the addition of soybean trypsin inhibitor ( $50 \mathrm{mg} / \mathrm{mL}$, Sigma). Cells were scraped off the plate and centrifuged at $500 \mathrm{rpm}$ at $4{ }^{\circ} \mathrm{C}$ for $5 \mathrm{~min}$. The cell pellet was lysed in gel electrophoresis sample buffer, heated to $95^{\circ} \mathrm{C}$ for $5 \mathrm{~min}$, and VEGFR-2 protein was analyzed by SDS-PAGE and Western blot using VEGFR-2 antibody (2479, Cell Signaling).

\subsection{Statistical Analysis}

Statistical analysis was performed using GraphPad Prism 7 (GraphPad Software Inc., San Diego, CA, USA). Data was investigated by ordinary 1-way ANOVA using Dunnett's test for multiple comparison and presented as mean \pm SD shown by error bars. All results represent mean of three experiments unless indicated differently. Results with $p$ values $<0.05$ were considered statistically significant and marked with an asterisk $\left(^{*}\right)$.

\section{Conclusions}

In summary, a range of novel antibody fragments in the form of highly specific anti-VEGFR-2 scFvs has been described, and the functional effects of allosteric inhibition of VEGFR-2 were characterized. The ability of scFvs to selectively block VEGF signaling via binding to an extracellular allosteric site in the cognate receptor, and their use in antibody-mediated drug delivery systems, document their potential for future therapeutic applications. At the mechanistic level, our findings provide the proof-of-principle that anti-VEGFR-2 agents targeting the membrane-proximal Ig-domains D2-3, D6, or D7, downregulate receptor activity independent of ligand binding and thus represent a novel strategy to target VEGFR-2 signaling.

Supplementary Materials: Supplementary materials can be found at http:/ / www.mdpi.com/1422-0067/19/5/ 1334/s1.

Author Contributions: K.B.-H., C.A.C.H. and D.A. conceived and designed the experiments; D.A., C.A.C.H. and T.S. performed the experiments; D.A. and C.A.C.H. analyzed the data; D.A. wrote the paper.

Acknowledgments: We thank Dario Neri for phage library, Patric Turowski for providing us with trypsin digestion protocol, Sandra Markovic-Mueller for assistance in A7 subcloning, Jonas Mechtersheimer for assisting protein purification, and Aurélien Rizk for advice with Squassh analysis. This work was supported by grants from Schweizerischer Nationalfonds zur Förderung der Wissenschaftlichen Forschung (31003A_152908 to KB-H and PMCDP3-134208/1 to CACH) and Oncosuisse (KLS-3569-02-2015 to KB-H).

Conflicts of Interest: The authors declare no conflict of interest.

$\begin{array}{ll}\text { Abbreviations } & \\ \text { BSA } & \text { Bovine serum albumin } \\ \text { CDR } & \text { Complementarity determining region } \\ \text { DARPins } & \text { Designed ankyrin repeat proteins } \\ \text { DMEM } & \text { Dulbecco's modified eagle's medium } \\ \text { ECD } & \text { Extracellular domain } \\ \text { E. coli } & \text { Escherichia coli } \\ \text { EGFR } & \text { Epidermal growth factor receptor } \\ \text { ELISA } & \text { Enzyme linked immunosorbent assay } \\ \text { Fab } & \text { Fragment antigen binding } \\ \text { FSEC } & \text { Fluorescence size-exclusion chromatography } \\ \text { HEK293 } & \text { Human embryonic kidney cells 293 } \\ \text { HER2 } & \text { Human epidermal growth factor receptor 2 } \\ \text { HRP } & \text { Horseradish peroxidase } \\ \text { HUVECs } & \text { Human umbilical vein endothelial cells } \\ \text { IgG } & \text { Immunoglobulin G } \\ \text { IPTG } & \text { Isopropyl } \beta \text {-D-1-thiogalactopyranoside }\end{array}$




$\begin{array}{ll}\text { ITC } & \text { Isothermal titration calorimetry } \\ \text { KDR } & \text { Kinase insert domain receptor } \\ \text { OD } & \text { Optical density } \\ \text { PAE-KDR } & \text { Porcine aortic endothelial cells overexpressing VEGFR-2 } \\ \text { PBS } & \text { Phosphate buffered saline } \\ \text { PCR } & \text { Polymerase chain reaction } \\ \text { PLC } \gamma & \text { Phospholipase C gamma } \\ \text { PVDF } & \text { Polyvinylidene fluoride } \\ \text { ScFv } & \text { Single chain variable fragment } \\ \text { SDS-PAGE } & \text { Sodium dodecylsulfate polyacrylamide gel electrophoresis } \\ \text { SEC } & \text { Size-exclusion chromatography } \\ \text { VEGF } & \text { Vascular endothelial growth factor } \\ \text { VEGFR } & \text { VEGF receptor } \\ \text { V } / V_{L} & \text { Antibody heavy/light chain variable region }\end{array}$

\section{References}

1. Hurwitz, H.; Fehrenbacher, L.; Novotny, W.; Cartwright, T.; Hainsworth, J.; Heim, W.; Berlin, J.; Baron, A.; Griffing, S.; Holmgren, E.; et al. Bevacizumab plus Irinotecan, Fluorouracil, and Leucovorin for Metastatic Colorectal Cancer. N. Engl. J. Med. 2004, 350, 2335-2342. [CrossRef] [PubMed]

2. Fuchs, C.S.; Tomasek, J.; Yong, C.J.; Dumitru, F.; Passalacqua, R.; Goswami, C.; Safran, H.; Dos Santos, L.V.; Aprile, G.; Ferry, D.R.; et al. Ramucirumab monotherapy for previously treated advanced gastric or gastro-oesophageal junction adenocarcinoma (REGARD): An international, randomised, multicentre, placebo-controlled, phase 3 trial. Lancet 2014, 383, 31-39. [CrossRef]

3. Wilke, H.; Muro, K.; Van Cutsem, E.; Oh, S.-C.; Bodoky, G.; Shimada, Y.; Hironaka, S.; Sugimoto, N.; Lipatov, O.; Kim, T.-Y.; et al. Ramucirumab plus paclitaxel versus placebo plus paclitaxel in patients with previously treated advanced gastric or gastro-oesophageal junction adenocarcinoma (RAINBOW): A double-blind, randomised phase 3 trial. Lancet Oncol. 2014, 15, 1224-1235. [CrossRef]

4. Mendel, D.B.; Laird, A.D.; Xin, X.; Louie, S.G.; Christensen, J.G.; Li, G.; Schreck, R.E.; Abrams, T.J.; Ngai, T.J.; Lee, L.B.; et al. In vivo antitumor activity of SU11248, a novel tyrosine kinase inhibitor targeting vascular endothelial growth factor and platelet-derived growth factor receptors: Determination of a pharmacokinetic/pharmacodynamic relationship. Clin. Cancer Res. 2003, 9, 327-337. [PubMed]

5. Shinkai, A.; Ito, M.; Anazawa, H.; Yamaguchi, S.; Shitara, K.; Shibuya, M. Mapping of the Sites Involved in Ligand Association and Dissociation at the Extracellular Domain of the Kinase Insert Domain-containing Receptor for Vascular Endothelial Growth Factor. J. Biol. Chem. 1998, 273, 31283-31288. [CrossRef] [PubMed]

6. Fuh, G.; Li, B.; Crowley, C.; Cunningham, B.; Wells, J.A. Requirements for binding and signaling of the kinase domain receptor for vascular endothelial growth factor. J. Biol. Chem. 1998, 273, 11197-11204. [CrossRef] [PubMed]

7. Kisko, K.; Brozzo, M.S.; Missimer, J.; Schleier, T.; Menzel, A.; Leppänen, V.-M.; Alitalo, K.; Walzthoeni, T.; Aebersold, R.; Ballmer-Hofer, K. Structural analysis of vascular endothelial growth factor receptor-2/ligand complexes by small-angle X-ray solution scattering. FASEB J. 2011, 25, 2980-2986. [CrossRef] [PubMed]

8. Ruch, C.; Skiniotis, G.; Steinmetz, M.O.; Walz, T.; Ballmer-Hofer, K. Structure of a VEGF-VEGF receptor complex determined by electron microscopy. Nat. Struct. Mol. Biol. 2007, 14, 249-250. [CrossRef] [PubMed]

9. Yang, Y.; Xie, P.; Opatowsky, Y.; Schlessinger, J. Direct contacts between extracellular membrane-proximal domains are required for VEGF receptor activation and cell signaling. Proc. Natl. Acad. Sci. USA 2010, 107, 1906-1911. [CrossRef] [PubMed]

10. Brozzo, M.S.; Leppanen, V.M.; Winkler, F.K.; Ballmer-Hofer, K. VEGFR-2/VEGF-A COMPLEX STRUCTURE. 3V2A 2012. [CrossRef]

11. Hyde, C.A.C.; Giese, A.; Stuttfeld, E.; Abram Saliba, J.; Villemagne, D.; Schleier, T.; Binz, H.K.; Ballmer-Hofer, K. Targeting Extracellular Domains D4 and D7 of Vascular Endothelial Growth Factor Receptor 2 Reveals Allosteric Receptor Regulatory Sites. Mol. Cell. Biol. 2012, 32, 3802-3813. [CrossRef] [PubMed] 
12. Thieltges, K.M.; Avramovic, D.; Piscitelli, C.L.; Markovic-Mueller, S.; Binz, H.K.; Ballmer-Hofer, K. Characterization of a drug-targetable allosteric site regulating vascular endothelial growth factor signaling. Angiogenesis 2018, 38, 1-11. [CrossRef] [PubMed]

13. Kendrew, J.; Eberlein, C.; Hedberg, B.; McDaid, K.; Smith, N.R.; Weir, H.M.; Wedge, S.R.; Blakey, D.C.; Foltz, I.; Zhou, J.; et al. An antibody targeted to VEGFR-2 Ig domains 4-7 inhibits VEGFR-2 activation and VEGFR-2-dependent angiogenesis without affecting ligand binding. Mol. Cancer Ther. 2011, 10, 770-783. [CrossRef] [PubMed]

14. Marks, J.D.; Hoogenboom, H.R.; Bonnert, T.P.; McCafferty, J.; Griffiths, A.D.; Winter, G. By-passing immunization. Human antibodies from V-gene libraries displayed on phage. J. Mol. Biol. 1991, 222, 581-597. [CrossRef]

15. Rosenblum, L.T.; Choyke, P.L.; Kobayashi, H. Quantitative and specific molecular imaging of cancer with labeled engineered monoclonal antibody fragments. Ther. Deliv. 2011, 2, 345-358. [CrossRef] [PubMed]

16. Yokota, T.; Milenic, D.E.; Whitlow, M.; Schlom, J. Rapid tumor penetration of a single-chain Fv and comparison with other immunoglobulin forms. Cancer Res. 1992, 52, 3402-3408. [PubMed]

17. Thurber, G.M.; Schmidt, M.M.; Wittrup, K.D. Antibody tumor penetration: Transport opposed by systemic and antigen-mediated clearance. Adv. Drug Deliv. Rev. 2008, 60, 1421-1434. [CrossRef] [PubMed]

18. Monnier, P.; Vigouroux, R.; Tassew, N. In Vivo Applications of Single Chain Fv (Variable Domain) (scFv) Fragments. Antibodies 2013, 2, 193-208. [CrossRef]

19. Kim, H.-Y.; Wang, X.; Wahlberg, B.; Edwards, W.B. Discovery of hapten-specific scFv from a phage display library and applications for HER2-positive tumor imaging. Bioconjug. Chem. 2014, 25, 1311-1322. [CrossRef] [PubMed]

20. Li, X.; Stuckert, P.; Bosch, I.; Marks, J.D.; Marasco, W.A. Single-chain antibody-mediated gene delivery into ErbB2-positive human breast cancer cells. Cancer Gene Ther. 2001, 8, 555-565. [CrossRef] [PubMed]

21. Safdari, Y.; Ahmadzadeh, V. Use of Single-Chain Antibody Derivatives for Targeted Drug Delivery. Mol. Med. 2016, 22, 258-270. [CrossRef] [PubMed]

22. Silacci, M.; Brack, S.; Schirru, G.; Mårlind, J.; Ettorre, A.; Merlo, A.; Viti, F.; Neri, D. Design, construction, and characterization of a large synthetic human antibody phage display library. Proteomics 2005, 5, 2340-2350. [CrossRef] [PubMed]

23. Böldicke, T.; Tesar, M.; Griesel, C.; Rohde, M.; Gröne, H.J.; Waltenberger, J.; Kollet, O.; Lapidot, T.; Yayon, A.; Weich, H. Anti-VEGFR-2 scFvs for Cell Isolation. Single-Chain Antibodies Recognizing the Human Vascular Endothelial Growth Factor Receptor-2 (VEGFR-2/flk-1) on the Surface of Primary Endothelial Cells and Preselected CD34+ Cells from Cord Blood. Stem Cells 2001, 19, 24-36. [CrossRef] [PubMed]

24. Lu, D.; Jimenez, X.; Zhang, H.; Bohlen, P.; Witte, L.; Zhu, Z. Selection of high affinity human neutralizing antibodies to VEGFR2 from a large antibody phage display library for antiangiogenesis therapy. Int. J. Cancer 2002, 97, 393-399. [CrossRef] [PubMed]

25. Lu, D.; Shen, J.; Vil, M.D.; Zhang, H.; Jimenez, X.; Bohlen, P.; Witte, L.; Zhu, Z. Tailoring in vitro selection for a picomolar affinity human antibody directed against vascular endothelial growth factor receptor 2 for enhanced neutralizing activity. J. Biol. Chem. 2003, 278, 43496-43507. [CrossRef] [PubMed]

26. Cobo, M.; Gutiérrez, V.; Villatoro, R.; Trigo, J.M.; Ramos, I.; López, O.; Ruiz, M.; Godoy, A.; López, I.; Arroyo, M. Spotlight on ramucirumab in the treatment of nonsmall cell lung cancer: Design, development, and clinical activity. Lung Cancer (Auckl.) 2017, 8, 57-66. [CrossRef] [PubMed]

27. Tabernero, J.; Yoshino, T.; Cohn, A.L.; Obermannova, R.; Bodoky, G.; Garcia-Carbonero, R.; Ciuleanu, T.-E.; Portnoy, D.C.; Van Cutsem, E.; Grothey, A.; et al. Ramucirumab versus placebo in combination with second-line FOLFIRI in patients with metastatic colorectal carcinoma that progressed during or after first-line therapy with bevacizumab, oxaliplatin, and a fluoropyrimidine (RAISE): A randomised, double-blind, multicentre, phase 3 study. Lancet Oncol. 2015, 16, 499-508. [PubMed]

28. Zhou, Y.; Drummond, D.C.; Zou, H.; Hayes, M.E.; Adams, G.P.; Kirpotin, D.B.; Marks, J.D. Impact of single-chain $\mathrm{Fv}$ antibody fragment affinity on nanoparticle targeting of epidermal growth factor receptor-expressing tumor cells. J. Mol. Biol. 2007, 371, 934-947. [CrossRef] [PubMed]

29. Wang, X.; Kim, H.-Y.; Wahlberg, B.; Edwards, W.B. Selection and characterization of high affinity VEGFR1 antibodies from a novel human binary code scFv phage library. Biochem. Biophys. Rep. 2015, 3, 169-174. [CrossRef] [PubMed] 
30. Young, N.M.; MacKenzie, C.R.; Narang, S.A.; Oomen, R.P.; Baenziger, J.E. Thermal stabilization of a single-chain Fv antibody fragment by introduction of a disulphide bond. FEBS Lett. 1995, 377, 135-139. [CrossRef]

31. Glockshuber, R.; Schmidt, T.; Plückthun, A. The disulfide bonds in antibody variable domains: Effects on stability, folding in vitro, and functional expression in Escherichia coli. Biochemistry 1992, 31, 1270-1279. [CrossRef] [PubMed]

32. Tan, P.H.; Sandmaier, B.M.; Stayton, P.S. Contributions of a highly conserved VH/VL hydrogen bonding interaction to scFv folding stability and refolding efficiency. Biophys. J. 1998, 75, 1473-1482. [CrossRef]

33. Brinkmann, U.; Di Carlo, A.; Vasmatzis, G.; Kurochkina, N.; Beers, R.; Lee, B.; Pastan, I. Stabilization of a recombinant $\mathrm{Fv}_{\mathrm{V}}$ fragment by base-loop interconnection and $\mathrm{V}(\mathrm{H}) \mathrm{V}(\mathrm{L})$ permutation. J. Mol. Biol. 1997, 268, 107-117. [CrossRef] [PubMed]

34. Friedman, L.M.; Rinon, A.; Schechter, B.; Lyass, L.; Lavi, S.; Bacus, S.S.; Sela, M.; Yarden, Y. Synergistic down-regulation of receptor tyrosine kinases by combinations of mAbs: Implications for cancer immunotherapy. Proc. Natl. Acad. Sci. USA 2005, 102, 1915-1920. [CrossRef] [PubMed]

35. Baselga, J.; Albanell, J. Mechanism of action of anti-HER2 monoclonal antibodies. Ann. Oncol. 2001, 12, S35-S41. [CrossRef] [PubMed]

36. Drebin, J.A.; Link, V.C.; Stern, D.F.; Weinberg, R.A.; Greene, M.I. Down-modulation of an oncogene protein product and reversion of the transformed phenotype by monoclonal antibodies. Cell 1985, 41, 695-706. [CrossRef]

37. Hudziak, R.M.; Lewis, G.D.; Winget, M.; Fendly, B.M.; Shepard, H.M.; Ullrich, A. p185HER2 monoclonal antibody has antiproliferative effects in vitro and sensitizes human breast tumor cells to tumor necrosis factor. Mol. Cell. Biol. 1989, 9, 1165-1172. [CrossRef] [PubMed]

38. Zhu, W.; Okollie, B.; Artemov, D. Controlled internalization of Her-2/ neu receptors by cross-linking for targeted delivery. Cancer Biol. Ther. 2007, 6, 1960-1966. [CrossRef] [PubMed]

39. Bertelsen, V.; Stang, E. The Mysterious Ways of ErbB2/HER2 Trafficking. Membranes (Basel) 2014, 4, 424-446. [CrossRef] [PubMed]

40. Sarabipour, S.; Ballmer-Hofer, K.; Hristova, K. VEGFR-2 conformational switch in response to ligand binding. eLife 2016, 5, e13876. [CrossRef] [PubMed]

41. Nellis, D.F.; Ekstrom, D.L.; Kirpotin, D.B.; Zhu, J.; Andersson, R.; Broadt, T.L.; Ouellette, T.F.; Perkins, S.C.; Roach, J.M.; Drummond, D.C.; et al. Preclinical manufacture of an anti-HER2 scFv-PEG-DSPE, liposome-inserting conjugate. 1. Gram-scale production and purification. Biotechnol. Prog. 2005, 21, 205-220. [CrossRef] [PubMed]

42. Viardot, A.; Goebeler, M.-E.; Hess, G.; Neumann, S.; Pfreundschuh, M.; Adrian, N.; Zettl, F.; Libicher, M.; Sayehli, C.; Stieglmaier, J.; et al. Phase 2 study of the bispecific T-cell engager (BiTE) antibody blinatumomab in relapsed/refractory diffuse large B-cell lymphoma. Blood 2016, 127, 1410-1416. [CrossRef] [PubMed]

43. Goebeler, M.-E.; Knop, S.; Viardot, A.; Kufer, P.; Topp, M.S.; Einsele, H.; Noppeney, R.; Hess, G.; Kallert, S.; Mackensen, A.; et al. Bispecific T-Cell Engager (BiTE) Antibody Construct Blinatumomab for the Treatment of Patients with Relapsed/Refractory Non-Hodgkin Lymphoma: Final Results From a Phase I Study. J. Clin. Oncol. 2016, 34, 1104-1111. [CrossRef] [PubMed]

44. Miller, K.; Cortes, J.; Hurvitz, S.A.; Krop, I.E.; Tripathy, D.; Verma, S.; Riahi, K.; Reynolds, J.G.; Wickham, T.J.; Molnar, I.; et al. HERMIONE: A randomized Phase 2 trial of MM-302 plus trastuzumab versus chemotherapy of physician's choice plus trastuzumab in patients with previously treated, anthracycline-naïve, HER2-positive, locally advanced/metastatic breast cancer. BMC Cancer 2016, 16, 320. [CrossRef] [PubMed]

45. Pini, A.; Viti, F.; Santucci, A.; Carnemolla, B.; Zardi, L.; Neri, P.; Neri, D. Design and use of a phage display library. Human antibodies with subnanomolar affinity against a marker of angiogenesis eluted from a two-dimensional gel. J. Biol. Chem. 1998, 273, 21769-21776. [CrossRef] [PubMed]

46. Rizk, A.; Paul, G.; Incardona, P.; Bugarski, M.; Mansouri, M.; Niemann, A.; Ziegler, U.; Berger, P.; Sbalzarini, I.F. Segmentation and quantification of subcellular structures in fluorescence microscopy images using Squassh. Nat. Protoc. 2014, 9, 586-596. [CrossRef] [PubMed]

(C) 2018 by the authors. Licensee MDPI, Basel, Switzerland. This article is an open access article distributed under the terms and conditions of the Creative Commons Attribution (CC BY) license (http:/ / creativecommons.org/licenses/by/4.0/). 